Theor. Appl. Climatol. 41, $121-127$ (1990)

Theoretical and Applied Climatology

(C) by Springer-Verlag 1990

551.586 .58

${ }^{1}$ Istituto TESRE-CNR, Bologna, Italy

${ }^{2}$ Department of Material Science, Lecce University, Italy

${ }^{3}$ Physics Department, Bologna University, Italy

${ }^{4}$ Istituto FISBAT-CNR, Bologna, Italy and

${ }^{5}$ Swiss Federal Institute of Forestry Research, Birmensdorf, Switzerland

\title{
The Relationship Between Climatic Variables and Wood Structure in Pinus Halepensis Mill.
}

\section{I-Effects of Humidity and Temperature}

\author{
M. R. Attolini ${ }^{1}$, F. Calvani ${ }^{2}$, M. Galli ${ }^{3}$, T. Nanni ${ }^{4}$, L. Ruggiero ${ }^{2}$, E. Schaer ${ }^{5}$, and F. Zuanni ${ }^{2}$ \\ With 6 Figures
}

Received February 22, 1988

Revised July 23, 1989

\begin{abstract}
Summary
The weekly increments under various conditions of a dozen of 30 to 60 years old Halep pines grown in the Lecce area have been measured during two years with a band dendrometer. The data have been compared with the X-ray density of a stem in radial direction, the weekly precipitations and the integrated temperature excess above $8^{\circ} \mathrm{C}$. We have found that growth rate behaviour is practically the same for all the pines considered. This indicate a strict dependence of growth on external factors such as climate and other environmental conditions. Vegetation activity does not seem to have regular dormancy periods: it stops when temperature and humidity become prohibitive and resumes as soon as they become favourable. The volume of wood formed in late-season (JulyJanuary) equals more or less that of early-season (FebruaryJune), whereas the wood mass and the number of cells in late-season is nearly double of that in early-season. During periods of high cambial activity one observes a lower cell lignification. However, on the whole, the photoperiodicity hypothesis in lignification seems to be confirmed. The growth rate appears inversely related to density. The lignification process appears to extend to the outer xylem layer of $1-2 \mathrm{~mm}$ and seems most effective during dry and warm seasons when cambial activity is low. Density wriggles appear to derive from combined variations of cambial activity, cell size and lignification, mostly corresponding to environmental events such as periods of drought or of cold weather. Finally, during
\end{abstract}

the dry seasons we find that a precipitation event is generally followed within a time less than a week, by an increase of growth rate. Whereas during the wet season the growth rate variation is very similar to that of temperature excess.

\section{Introduction}

Dendroclimatology has successfully explained 30$40 \%$ of tree ring variance by mean temperature and precipitation during the growth season. Conversely, it has permitted the reconstruction of temperatures and precipitations from growth ring width series (Fritts, 1976; Hughes et al., 1982).

However, in the Mediterranean area, especially for food production, it is also very important to know how temperature and precipitation are distributed through the year. The ultimate objective of our research is, therefore, to find additional information on seasonal variation of climatic variables through the analysis of density and geometric structure of growth rings of trees. First of all this requires the solution of the direct problem, i.e. how environmental factors (such as temper- 
ature, light intensity, daylenght duration, soil moisture, air humidity, etc.) and their variation affect wood formation and structure.

For this purpose we are studying the growth of Halep pine (Pinus Halepensis Mill.) in Southern Italy where it has a year-long vegetation period.

Observations of Halep pine growth in relation with humidity and temperature have been already made on yearly basis by Oppenheimer (1945) in Israel, by Messeri (1948) in Bari (Italy) and by Serre (1976) in Marseille (France).

Observations of environmental effects on growth ring structure for Pinus ponderosa in an arid site of Arizone have been reported by Fritts (1976). He qualitatively reports on size and wall thickness of tracheids and their relation to external factors like temperature, solar radiation, soil moisture and precipitation. He concludes that environmental information locked in cell structure of annual rings is not always easy to disentangle from the complexity of cell growth and that wood density variations should help in its understanding.

Müller (1981) has studied the growth during an entire vegetation period of three conifer species (larch, spruce, and pine) near the timberline in the Simplon region of Switzerland. He finds similar growth patterns for the three species and a dominating influence of temperature whose effects on growth appears to be delayed from two to seven days.

In this paper we present the first results of relations on weekly basis of observations of tree ring growth, X-ray density and climatic environment in Halep pines grown in the Lecce area.

\section{Materials and Methods}

Since 1983 we have taken weekly measurements of stem circumference increments of a dozen Halep pines. The trees aged from 30 to 60 years are located at about $5 \mathrm{~km}$ west from Lecce (Southern Italy) on rendzina soil about $40 \mathrm{~cm}$ thick on pliocenic organogenic calcarenite. The Walter diagram of Lecce obtained from 30-40 years of observations is shown in Fig. 1 (Walter and Lieth, 1960).

Four trees aged about 30 years were isolated and grew in an open area with a rather globular crown; the remaining trees, including the one considered below (P 3) were surrounded by other trees and therefore rather long limbed.

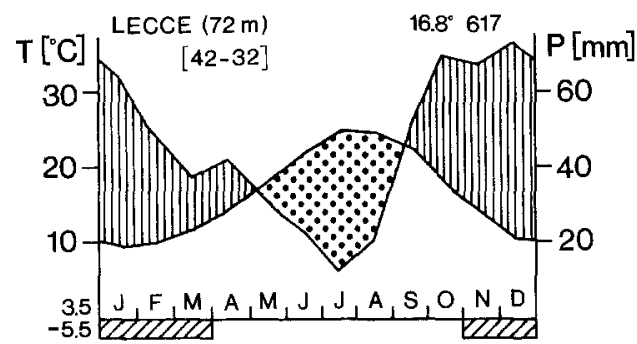

Fig. 1. Temperature $(T)$ and precipitation $(P)$ as given in the Walter diagram of Lecce (adapted from Walter and Lieth, 1960). Notice the dotted region indicating the average length of the season with water deficit

The circumference dendrometers are made of a $2 \mathrm{~cm}$ wide stainless steel band. They were placed at a height of about $1.5 \mathrm{~m}$ on the tree, and stretched by a stainless steel spring with a tension of 1 to $4 \mathrm{~kg}$. The corresponding mean pressure on the stem considering a circumference of the order of $1 \mathrm{~m}$ was about 20 to $80 \mathrm{~g} / \mathrm{cm}^{2}$. The spring was usually reset after reaching its maximum extension. Increments were measured to $0.1 \mathrm{~mm}$ with a $0.05 \mathrm{~mm}$ gauge. In order to avoid a friction effect, the dendrometer was oiled in its sliding parts.

The measurements were made every Monday between 9.00 and 10.00 in the morning, except during the Christmas, New Year and mid-August holidays.

Temperatures were measured with a thermograph in a standard meteorological shelter in the immediate vicinity of $\mathrm{P} 3$ and at a distance of about $1 \mathrm{~km}$ from the remaining trees.

Weekly temperature excess over $8^{\circ} \mathrm{C}$ was also computed, i.e. the area enclosed between the weekly thermogram line higher than $8^{\circ} \mathrm{C}$ and the $8^{\circ} \mathrm{C}$ line, measured in $\left[{ }^{\circ} \mathrm{C} \cdot \mathrm{h}\right]$. We chose that figure because under $8^{\circ} \mathrm{C}$ we assume a stasis of cambial activity.

Precipitation was measured near the shelter with a standard pluviograph.

Soil moisture at various depths from 25 to $40 \mathrm{~cm}$ was measured twice a day in various positions around $\mathrm{P} 3$ through the resistivity of porous blocks of the Bouyoucos type.

The variable appearance of any annual ring growth of an Halep pine in normal health condition is well described by the average local density of wood.

Wood density was measured by the Swiss Federal Institute of Forestry Research at Birmensdorf, 


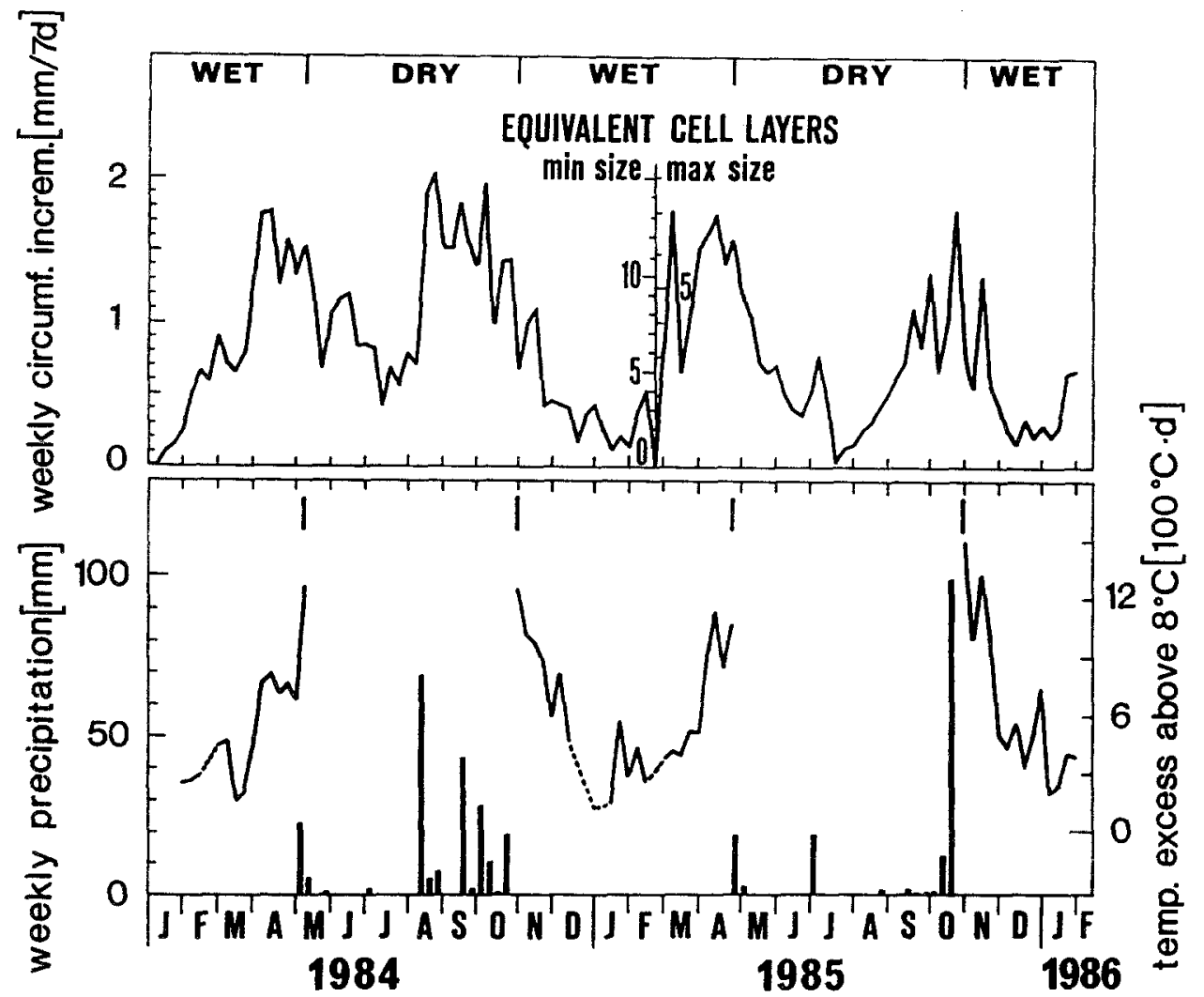

Fig. 2. Upper section: Average weekly growth of four open grown Halep pines 30 to 60 years old, placed at $5 \mathrm{~km}$ west of Lecce during the years 1984 and 1985 . Scales in the centre refer to the equivalent number of cell layers differentiated per week computed according to the minimum or to the maximum cell size found across the annual limit of rings (latewood-earlywood limit). Limits of wet and dry season found by Bouyoucos blocks are also indicated.

Lower section: Temperature excesses during the wet season over $8^{\circ} \mathrm{C}$ in a meteorological shelter placed at a distance of $1 \mathrm{~km}$. Vertical bars indicate weekly precipitation during the dry season

Zürich, with an X-ray densitometer. It was obtained (see Lenz et al., 1976) by scanning an Xray contact picture with a microphotodensitometer equipped with a $0.03 \times 1 \mathrm{~mm}^{2}$ slit, of a longitudinal slide $3 \mathrm{~mm}$ thick, obtained from a radial core. Densities in steps of $0.1 \mathrm{~mm}$ are the means obtained through a window of $0.1 \times 1 \mathrm{~mm}^{2}$. Such a window contained from 60 to 130 cells according to their dimension (see below). Care has been taken to avoid resin ducts.

The possible length variation of the cores due to extraction, drying, immersion in alcohol for resin extraction, and preparation for X-rays, was checked by comparing the final length appearing in the X-ray plate with the length of the fresh core and with the depth of core holes up to cambium. The difference was of the order of a millimeter for nine rings i.e. negligible.

When summing the weekly radial growth $\Delta c_{i} /$
$2 \pi$ from the beginning of dendrometric measurements $\left(\Delta c_{i}\right)$, we simultaneously obtain the cumulative growth at the end of the $i$-th week and the corresponding dated positions along the radius. This also gives us the possibility of dating exactly the density record: i.e. to find the dates of differentiation of the cells corresponding to the point where density was measured (Fig. 5).

In order to illustrate possible relations between density and growth rate, the cumulative mean radial growth at the $i$-th week vs. the weekly growth at the same week (i.e. the growth rate as a function of radius), has been plotted in Fig. 5 a.

\section{Dendrometric and Environmental Observations}

The mean weekly circumference increments $\Delta c_{i}$ of the four open grown pines, weekly precipitation 
during the dry season, and weekly temperature excesses over $8{ }^{\circ} \mathrm{C}$ during the wet season over the period January 9, 1984 to February 3, 1986 are plotted in Fig. 2.

We assume that the maximum error on $\Delta c_{i}$ cannot exceed $0.1 \mathrm{~mm}$. In fact, as all dendrometers were kept oiled and negative increments of the order of $0.1 \mathrm{~mm}$ or more with eucaliptus, cypress and some not healthy Halep pines, were frequently observed, but never with pine $\mathrm{P} 3$ or younger pines, we reasonably deduced that weekly increment measurements should be reliable within the limits of instrumental sensitivity which is $0.1 \mathrm{~mm}$.

The limits of wet periods corresponding to conditions of fully soaked soil, are indicated by the soil humidity monitor.

Out of a total of 108 weeks of observation we found 102 weeks in which the variation of increment of at most one pine disagreed with the remaining three pines. In only 6 weeks the increments of two pines increased as the other two decreased.

The temperature effect during the wet season is shown by the agreement of temperature excess variation with growth rate variation. As it can be seen from Fig. 2 only for 6 weeks out of 46 the growth rate variation was found to be in disagreement with variation of temperature excess, which corresponds to a significance level of $10^{-7}$.

The response of growth rate to precipitation during the dry season (see Fig. 2) is significant and with a delay of the order of one week. In fact during the 25 weeks and 27 weeks of the dry seasons of 1984 and 1985, respectively, the mean growth rates for the rainy weeks were of $5.88 \pm 0.42$ and $3.88 \pm 0.45[0.1 \mathrm{~mm} /$ week units $]$, respectively, whereas for the weeks without rain we found $3.74 \pm 0.43$ and $1.73 \pm 0.22$ with a mean difference of $2.15 \pm 0.39$ [0.1 mm/week units], which is largely significant. Here, effects of internal or external hydration of stem appear negligible, because after the increments due to large precipitations we never observed negative increments i.e. shrinking.

The equivalent number of cell layers produced in a week can be estimated through the mean radial dimension of tracheids as shown in Fig. 2 and can reach the number of 10 to 15 during or soon after the summer resumption of cambial activity. In fact, the mean size of the cells in the radial direction that was measured across the annual limits of rings (late-earlywood limits) from a series of 20 measurements in core microphotographs of radial sections from four trees resulted in $21 \mu \mathrm{m}$ for latewood and $40 \mu \mathrm{m}$ for early wood.

\section{Densitometric Observations}

Figure 3 shows the X-ray densities in steps of $0.1 \mathrm{~mm}$ of pine $\mathrm{P} 3$ in northern and southern radial directions at $1.5 \mathrm{~m}$ from the ground during the years 1976-1984.

Annual cycles are well recognizable; density oscillations range from 0.45 to $1.00 \mathrm{~g} / \mathrm{cm}^{3}$.

The r.m.s. error level that can be attributed to instrumental error as well as to inhomogeneity of cell structure and distribution, is about $5.5 \mathrm{mg} \mathrm{cm}^{-3}$. It has been computed through the second differences of the terms of the original density series, per steps of $0.1 \mathrm{~mm}$.

The number of conspicuous density wriggles, which are similar to each other in the two cores and can be considered contemporary, is considerable (more than 50 for 9 years).

In the same Fig. 3 the change of density per steps of $0.1 \mathrm{~mm}$ is also plotted; it reflects the variation of radial diameter of tracheids and of their wall thickness, due to the combined effect off cell differentiation and lignification rates.

The average X-ray density for North-pointing and South-pointing cores has been obtained after cross-dating the two density records on the basis

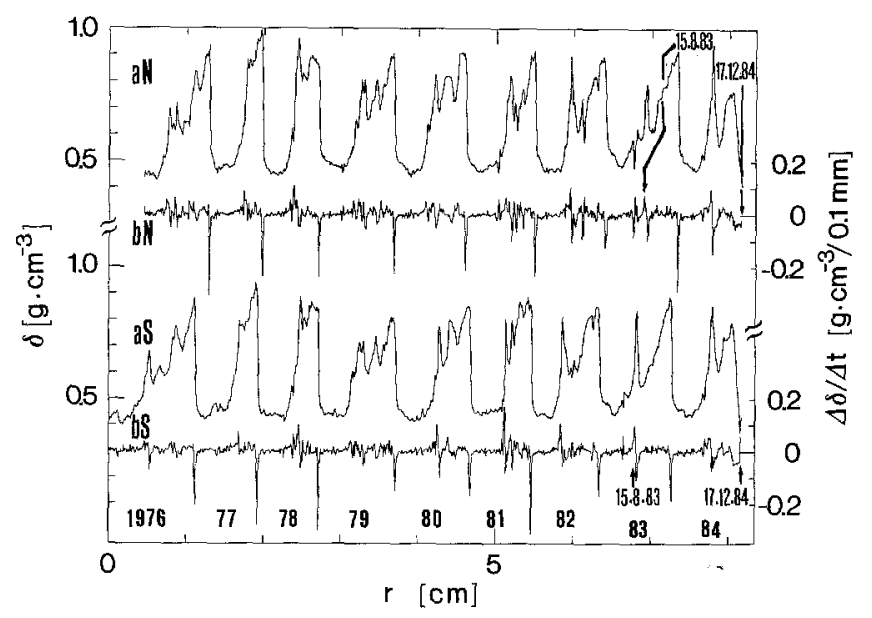

Fig. 3. aN), aS), $X$-ray density $\delta(r)$ of pine $\mathbf{P} 3$ in northern and southern radial direction $(r)$ at $1.5 \mathrm{~m}$ from the ground; bN), bS) density variation per radial steps of $0.1 \mathrm{~mm}$ (density radial derivative). Densities are averaged in a slit of $0.03 \times 1 \mathrm{~mm}^{2}$ perpendicular to the radius 


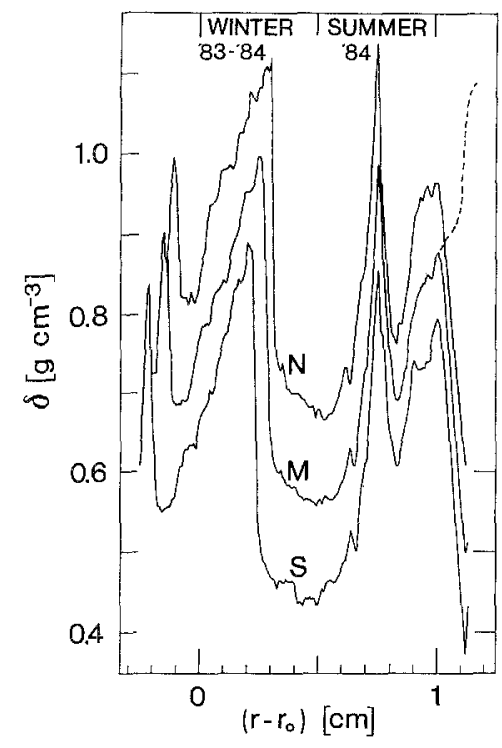

Fig. 4. Average density $\delta(r)$ of cores from pine $\mathrm{P} 3$ in the northern and southern directions obtained by cross-dating density events and assigning the mean radius to them. $\mathrm{N}$ : density vs. radius in northern direction; $S$ : density vs. radius in southern direction; $M$ : mean density along the mean value of radius. Standard error is shown to the left. The dashed line roughly indicates the expected density of last latewood cell layers after lignification is complete. For a better clarity the scales of $\mathrm{M}$ and $\mathrm{N}$ have been raised of 0.1 and $0.2 \mathrm{~g} \mathrm{~cm}^{-3}$, respectively

of the above-mentioned corresponding wriggles. In Fig. 4 we show the resulting mean for the period August 20, 1983-December 17, 1984 for which we have weekly growth records.

In Fig. 5 the weekly circumference increments plotted versus their progressive sum, the monthly increments, the series of the mean densities and of their first differences are represented. The maximum error for increments and the standard error limits for density and first differences of densities are also shown.

\section{Discussion}

The area under the mean growth rate curve (Fig. 2) indicates that in the four pines under investigation the total volume of xylem cells differentiated in the early season is roughly equivalent to that of the late season. Moreover, as the radial dimension of latewood tracheids is smaller than that of earlywood (see Fig. 2) one deduces that the number of cells differentiated during the late season is considerably higher than that of the early season.

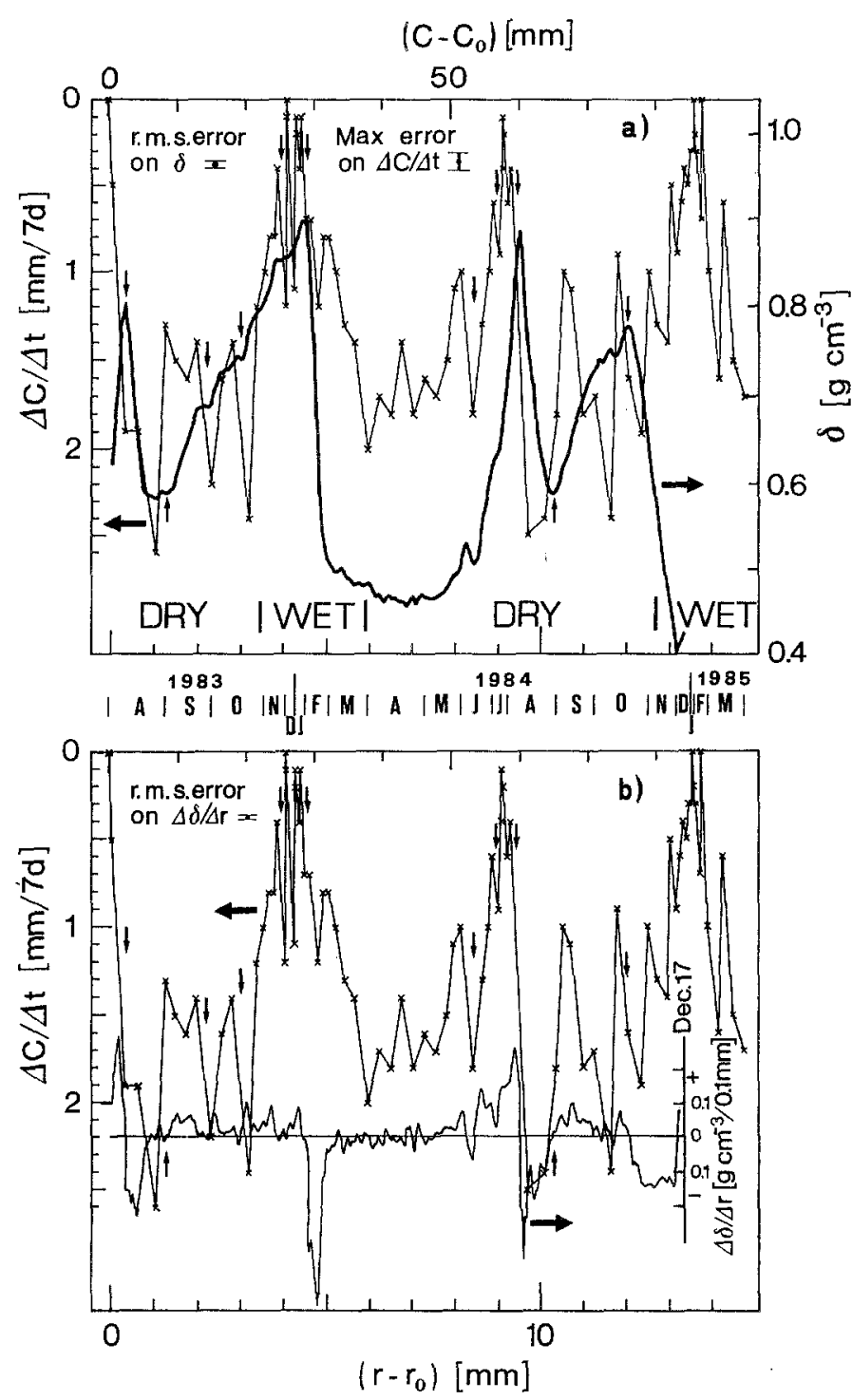

Fig. 5. Weekly circumference increments $\Delta C(-\mathrm{x}-)$ of pine P 3 compared (a) with its density in the radial direction (heavy line), and (b) with its radial density derivative. Monthly growth is also shown. Notice the inverted scale of $\Delta C$

The single growth curves and their average in Fig. 2 suggest that cambium activity may temporarily stop, but is always ready to resume activity as soon as temperature or humidity conditions become favourable. For instance, during the week including January 25, 1985, when temperature reached $-5^{\circ} \mathrm{C}$, but with some sunny days, we find a mean growth of $0.2 \mathrm{~mm}$.

The strong dependence of growth variation on common external conditions and its dependence on temperature and precipitation, suggests that in the Mediterranean area with a continuous water deficit (Fig. 1), at least for Halep pine, wood for- 


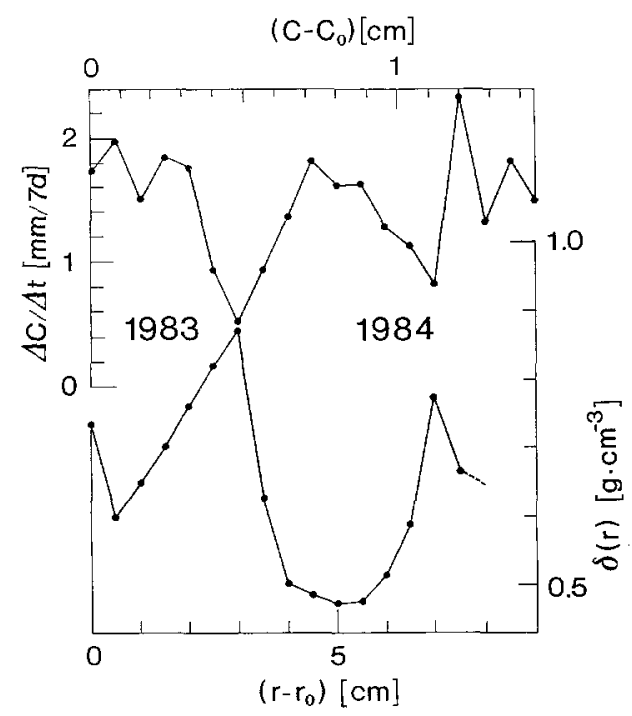

Fig. 6. Mean weekly growth rate and mean density per steps of $0.1 \mathrm{~mm}$ in the radial direction of the identical cores from P 3 as shown in Fig. 5.

mation reflects environment conditions for most part of the year.

The density grossly increasing from wood of early-season to wood of late-season (Fig. $5 \mathrm{a}$, heavy line) may be explained by the photoperiodic effect on cell wall thickening found by many authors as reported by Brown (1971).

Density wriggles (see arrow in Fig. 5 a), can be attributed both to variations of cell size and cell walls. They appear to be associated with strong variations of weekly growth, i.e. of cambial activity which in turn is mainly dependent on variations of temperature and soil humidity. One can therefore suppose that also all wriggles in the density plots of Fig. 3 appearing especially in latewood, are due to humidity and temperature events.

In Fig. 5 a, we also observe that when the increments (i.e. the weekly cell differentiation rate) are large, the density is generally low, and viceversa. This is rather well confirmed by Fig. 6 where we compare mean weekly growth rates and density, per radial steps of $0.5 \mathrm{~mm}$. Regions coresponding to resumption or enhancement of cambial activity (around January and August) correspond to low lignified cells.

In the same figure one must notice that in the period of October-December 17, 1984, which corresponds to the outer cell layers about $1.5 \mathrm{~mm}$ thick, the density curve drops to $0.4 \mathrm{~cm}^{-3}$ which is below the earlywood density level, while one would expect it to rise up to about $0.9 \mathrm{~g} \mathrm{~cm}^{-3}$ (see Fig. 3).

To explain this phenomenon we may assume that lignification (that causes a local enhancement of density) is a rather continuous process that acts on the outer cell layers. So when cambial activity decreases (low growth rate), each cell will undergo a longer lignification process and density will locally increase. Viceversa, when cambial activity increases, the outer layers of tracheids will undergo a lignification process of shorter duration and there will be a density decrease.

In other words, according to this model cell wall thickening, which is a cause of density increase, is a process that simultaneously involves only the outer layers of 30 to 70 cells, and has an efficiency which decreases toward the center. The process is always active with an intensity depending on temperature, humidity, and light radiation.

This point of view on lignification would be consistent with the model of lignin deposition reported by Denne and Dodd (1981). Wardrop (1981) and the findings of Larson (1964) about the independence of cell wall thickness and cell dimensions. In fact, if cell thickening process is independent of cell dimensions, it is also independent of cell differentiation rate.

Further important features can be observed comparing the series of growth rates with the one of prime differences of density series i.e. the radial density variation rate per steps of $0.1 \mathrm{~mm}$ (radial density derivative) that can be seen in Fig. 3 and more detailed in Fig. 5 b). Minima of growth rate (i.e. stasis of cell differentiation) correspond to positive values and peaks of radial density derivative, whereas negative peaks of radial density derivative (i.e. sharp decreases of density) are associated to high values of increments.

A temperature effect on cell wall thickening might also explain the higher positive peaks of radial density derivative during warm season and the lower positive peaks during the early season as can be seen from Fig. 3. Moreover one can also explain the positive peaks of density derivative preceeding a negative peak corresponding to a density drop (see Fig. 3) which are higher on the warm season than in the cold season. In fact, when differentiation stops or slows down, the density increase mainly due to wall thickening would become much greater in summer than in winter when temperatures are lower. Therefore a big negative 
peak, preceeded by a low positive peak, would then signify a winter ring limit. While an intraannual ring or "false ring" would show a negative peak preceeded by a strong positive peak.

Our lignification model would also explain the inverse relationship between earlywood thickness and minimum density found by Bräker (1981) for conifers of Alpine region in xerothermic sites. In fact a larger earlywood thickness is mostly related to a higher growth rate which would cause less lignified cells.

\section{Conclusions}

From our observations on weekly growth rate, Xray density and environment of the Halep pines, we can draw the following conclusions:

1. Growth rate is sensitive mainly to temperature variations during the wet season and to soil humidity variations during the dry season.

2. Volumes of earlywood and latewood production per year are nearly equivalent, the mass of latewood exceeds the mass of earlywood.

3. Cell differentiation and lignification is always active as soon as temperature and soil moisture become favourable.

4. There is some evidence that wall thickening occurs on the outer cell layers and seems to be a continuous process acting independently of cell differentiation. The process seems to be most effective during the warm seasons, when cambial activity is low due to moisture stress.

5. Density wriggles can be explained by combined effects of cambial activity, cell size variation and lignification activity, mostly corresponding to environmental events like dry or cold periods.

6. Positive peaks of radial density derivative, immediately preceeding the negative peaks at the beginning of earlywood seem generally smaller than the positive ones that we find before negative peaks at the resumption of vegetative growth at the end of summer dry period. This phenomenon, if general, could help to discriminate between annual and intraannual rings.

\section{Acknowledgements}

We are indebted to G. Dalessandro of the Biology Department of Lecce University, to F. H. Schweingruber and O. U. Bräker of Swiss Federal Institute of Forestry Research and to S. Valenziano of S.A.F. Center of Rome for helpful discussions.
The present work was partly supported by CEE and by the CNR project on Climatology and Natural Risks.

\section{References}

Bräker, O. U., 1981: Der Alterstrend bei Jahrringdichten und Jahrringbreiten von Nadelhölzern und sein Ausgleich. In: Radial growth in trees, IUFRO Symposium, Innsbruck Sept. 9-12, 1980, Vienna, 1981, 142/1, 75-102.

Brown, C. L., 1971: Secondary Growth, Growth Ring Formation. In: Trees Structure and Function, (M. H. Zimmermann and C. L. Brown, eds.) Berlin, Springer: 9198.

Denne, M.P., Dodd, R. S., 1981: The Environmental Control of Xylem Differentiation. In: Xylem Cell Development, (J. R. Barnet, ed.) London: Castle House Publication: 236255.

Francini, E, 1953: Il pino d'Aleppo in Puglia. Annali Fac. Agr. Univ. Bari, 8, 309416.

Fritts, H. C., 1976: Tree Ring and Climate, London: Academic Press 74-113.

Hughes, M. K., Kelly, P. M., Pilcher, J. R., La Marche Jr., V. C., eds., 1982: Climate from Tree Rings, London: Cambridge University Press: 223 pp.

Larson, P. R., 1964: Some indirect Effects of Environment on Wood Formation. In: The Formation of Wood in Forest Trees (M. H. Zimmermann, ed.). London, Academic Press: $345-361$.

Lenz, O., Schaer, E., Schweingruber, F. H., 1976: Methodische Probleme bei der radiographische-densitometrischen Bestimmung der Dichte und der Jahrringbreiten von Holz, Holzforschung, 30 (4), 114-123

Messeri, A., 1948: L'evoluzione della cerchia legnosa in Pinus halepensis Mill. in Bari, Nuovo Giornale Botanico Italiano, LV (1), 111-132.

Müller, H. N., 1981: Messungen zur Beziehung Klimafaktoren - Jahrringwachstum von Nadelbaumarten verschiedener waldgrenznaher Standorte. In: Radial growth in trees. IUFRO Symposium, Innsbruck Sept. 9--12, 1980 Vienna, 1981, 142/2, 327-355.

Oppenheimer, H. R., 1945: Cambial wood production in stems of Pinus halepensis. Palestine Journal of Botany, Rehovot Series, 2, 22-51.

Serre, F., 1976: Les rapports de la croissance et du climat chez le Pin d'Alep. Oecol. Plant, 11, 143-171

Walter, H., Lieth, H., 1960: Klimadiagram Weltatlas, Iena: Gustav Fischer Verlag.

Wardrop, A. B., 1981: Lignification and Xilogenesis. In: Xylem Cell Development, (Barnett J. R., ed.) Castle House Publications LTD, 120-127.

Authors' addresses: M. R. Attolini, Istituto TESRE-CNR, via Castagnoli 1, Bologna, Italy; F. Calvani, L. Ruggiero and F. Zuanni, Department of Material Science, Lecce University, Lecce, Italy; M. Galli, Physics Department, Bologna University, Bologna, Italy; T. Nanni, Istituto FISBAT-CNR, Via Castagnoli 1, Bologna, Italy; E. Schaer, Swiss Federal Institute of Forestry Research, Birmensdorf, Switzerland. 